\title{
Isolation of nine polymorphic microsatellite loci from the leaf beetle, Lema (Lema) coronata (Coleoptera: Chrysomelidae: Criocerinae)
}

\author{
Yоко MATSUMURA and IzUMI YAO*
} Laboratory of Systematic Entomology, Department of Ecology and Systematics, Graduate School of Agriculture,
Hokkaido University, Sapporo, Japan; e-mail: iyao@res.agr.hokudai.ac.jp

Key words. Chrysomelidae, Criocerinae, Lema (Lema) coronata, L. (L.) scuterallis, magnetic particles, genital evolution, offspring paternity

\begin{abstract}
Sexual selection is thought to result in an elongation of genitalia in insects. Part of the genitalia of the leaf beetle Lema (Lema) coronata Baly is approximately twice the body length in both sexes. Nine microsatellite loci were isolated from $L$. (L.) coronata for use in future studies on the correlation between genital length and reproductive success. The nine loci were polymorphic, with three to six alleles per locus recorded in 40 individuals. Observed heterozygosity ranged from 0.08 to 0.38 and expected heterozygosity from 0.51 to 0.75 . The non-exclusive probability of the second parent and the identity calculated from the set of loci were 0.011 and $<0.001$, respectively. A deviation from the Hardy-Weinberg equilibrium was detected at all nine loci, i.e. significant heterozygote deficiencies, and several hypotheses accounting for this are discussed. The isolated loci carried independent information. Five polymorphic loci were amplified in a related sympatric species, $L$. (L.) scutellaris, which has relatively short genitalia. These microsatellite makers will be used to determine the paternity of offspring of females multiply mated in the laboratory and compare the selection pressures operating on genital length in these closely related species.
\end{abstract}

\section{INTRODUCTION}

Lema (Lema) coronata Baly (Coleoptera: Chrysomelidae: Criocerinae) is an herbivorous beetle approximately $5 \mathrm{~mm}$ long, which feeds on commelinaceous plants (e.g. Murdannia keisak and Commelina communis) (Kimoto \& Takizawa, 1994). This species has a multivoltine life cycle with the adults appearing and reproducing on its host plants in late May. Extremely elongate genitalia, approximately twice the body length in both sexes, are characteristic of this species (Matsumura \& Suzuki, 2008; Matsumura \& Akimoto, 2009). Closely related species of Lema also have elongated genitalia that vary in length, e.g. $L$. coronata ca. 2 times and L. scutellaris ca. 0.4 times the body length. (Matsumura \& Suzuki, 2008). Moreover, in these species the lengths of the male and female genitalia are positively correlated (Matsumura \& Suzuki, 2008; Matsumura unpubl. data).

Sexual selection is the accepted driving force resulting in the elongation of genital parts and the variability observed in related species (Eberhard, 1985; Hosken \& Stockley, 2004). There are several studies on the selection pressures and the mechanisms responsible for the elongation of genital parts (Tadler, 1999; Gschwentner \& Tadler, 2000; Rodriguez et al., 2004; Kamimura, 2005). In order to determine whether selection has been the driving force, it is necessary to determine the correlation between the genital lengths of both sexes and reproductive success for $L$. (L.) coronata (Arnqvist, 1997). Multiple mating experiments, in which reproductive success is measured in terms of the proportion of progeny fathered by a second male (P2 value), is commonly used to evaluate this correlation (e.g. Arnqvist \& Danielsson, 1999; Danielsson \& Askenmo, 1999; Kamimura, 2005; Takami, 2007). Co-dominant genetic markers are a useful means of determining paternity in mating experiments (e.g. Kamimura, 2005; Takami, 2007). In particular, microsatellite markers are widely used in population genetics, forensic research and paternity identification. The methods used to isolate microsatellite loci are well developed (Zane et al., 2002). The aim of this study was to isolate microsatellite loci that could be used as markers for paternity analysis of offspring of $L$. (L.) coronata. In addition, cross-species amplification was tested using $L$. (L.) scutellaris, the elongation of whose genitalia is markedly different from that of $L$. (L.) coronata (Matsumura \& Suzuki, 2008).

\section{MATERIAL AND METHODS}

An enriched genome library was constructed using magnetic particles based on a modified protocol by Fischer \& Bachmann (1998). Genomic DNA was extracted from $L$. (L.) coronata using the DNeasy Blood \& Tissue Kit (Qiagen, Tokyo, Japan). DNA was extracted from a pool of $12 \mathrm{~L}$. coronata collected in the field from Murdannia keisak, which flourishes in paddy fields. Five micrograms of genomic DNA were digested with 50 U Sau3AI and the fragments ligated to Sau3AI cassettes (TaKaRa-Bio, Shiga, Japan). Polymerase chain reactions (PCRs) were performed with the Cassette Primer C1 (TaKaRaBio) in a MyCycler (Bio-Rad, Tokyo, Japan). The PCR products were resolved in binding buffer $(10 \mathrm{mM}$ Tris- $\mathrm{HCl}, 1$ mM EDTA, $100 \mathrm{mM} \mathrm{NaCl}, \mathrm{pH}$ 7.5) and hybridized to 5' biotinlabelled oligonucleotide probes $(\mathrm{CA})_{10}$ after denaturation. The hybrids were subsequently isolated by binding to streptavidin magnetic particles (Roche-Diagnostics, Tokyo, Japan). After rinsing the particles in washing buffer $(10 \mathrm{mM}$ Tris- $\mathrm{HCl}, 1 \mathrm{mM}$ EDTA, $1 \mathrm{M} \mathrm{NaCl}, \mathrm{pH} 7.5)$, target DNAs were recovered by resuspension in elution buffer $(6 \mathrm{M}$ Guanidine- $\mathrm{HCl})$ and PCR-amplified. The enriched fragments ranging from $400 \mathrm{bp}$ to $1000 \mathrm{bp}$ were ligated into BamHI-cut pUC118 and transformed into competent Escherichia coli cells (HST08 Premium Competent Cells, TaKaRa-Bio).

\footnotetext{
* Corresponding author.
} 
TABLE 1. Characteristics of the nine microsatellites of Lema (Lema) coronata.

\begin{tabular}{|c|c|c|c|c|c|c|c|c|c|c|c|c|c|c|}
\hline Locus & Repeat motif & Primer sequences $\left(5^{\prime}-3^{\prime}\right)$ & $N$ & $\mathrm{Na}$ & $\begin{array}{l}\text { Size } \\
\text { range } \\
\text { (bp) }\end{array}$ & $\begin{array}{l}\mathrm{Ta} \\
\left({ }^{\circ} \mathrm{C}\right)\end{array}$ & $H_{O}$ & $H_{E}$ & $\begin{array}{l}\text { Devia- } \\
\text { tions } \\
\text { from } \\
\text { HWE }\end{array}$ & $P I C$ & $N E-2 P$ & $N E-I$ & $F_{I S}$ & $\begin{array}{c}\text { GenBank } \\
\text { Accession } \\
\text { no. }\end{array}$ \\
\hline$c-01$ & $(\mathrm{GT})_{7}$ & $\begin{array}{l}\text { F: GCTAAAACGTTTGCGAATTT } \\
\text { R: CGCACCGAACCGTTTTAAT }\end{array}$ & 40 & 3 & $244-248$ & 50 & 0.1 & 0.51 & $* *$ & 0.442 & 0.742 & 0.308 & 0.807 & AB598815 \\
\hline Lc- 02 & $\begin{array}{l}(\mathrm{CCG})_{3} \ldots \\
(\mathrm{CCG})_{2} *\end{array}$ & & 40 & 5 & $238-246$ & 50 & 0.08 & 0.63 & $* *$ & 0.580 & 0.608 & 0.185 & 0.882 & AB598816 \\
\hline Lc-03 & $(\mathrm{CA})_{7}$ & $\begin{array}{l}\text { F: GACCC } \\
\text { R: GTTTC }\end{array}$ & 40 & 6 & $240-250$ & 50 & 0.3 & 0.69 & $* *$ & 0.644 & 0.543 & 0.140 & 0.570 & AB598817 \\
\hline Lc-04 & $(\mathrm{CA})_{8}$ & $\begin{array}{l}\text { F: GAGAT } \\
\text { R: CCTCG }\end{array}$ & 40 & 4 & $238-244$ & 50 & 0.38 & 0.66 & $* *$ & 0.582 & 0.621 & 0.190 & 0.432 & AB598818 \\
\hline Lc- 05 & GTGG(GT)6 & $\begin{array}{l}\text { F: TGGTCT } \\
\text { R: GGAAG }\end{array}$ & 40 & 6 & $242-252$ & 50 & 0.38 & 0.72 & ** & 0.668 & 0.521 & 0.128 & 0.485 & AB598819 \\
\hline 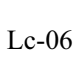 & $(\mathrm{CA})_{2} \mathrm{CT}(\mathrm{CA}$ & $\begin{array}{l}\text { F: AGTACGGCGCCCTGAATG } \\
\text { R: TATCCTGTGCTGGGGTTGG }\end{array}$ & 40 & 6 & $246-254$ & 56 & 0.23 & 0.75 & $* *$ & 0.702 & 0.488 & 0.108 & 0.704 & AB598820 \\
\hline & T & $\begin{array}{l}\text { F: CTACCCGCTATCGGTAATCG } \\
\text { R: CGTCTACGGTCACTGGGAAT }\end{array}$ & 40 & 3 & 210 & 56 & 0.23 & 0.60 & $* *$ & 0.517 & 0.688 & 0.241 & 0.627 & AB598821 \\
\hline Lc- 08 & $(\mathrm{CA})_{8}$ & $\begin{array}{l}\text { F: AAAACACGTCGTTGTTGCAG } \\
\text { R: GAACGGAATGAGGCCATCTA }\end{array}$ & 40 & 4 & $234-240$ & 50 & 0.18 & 0.56 & $* *$ & 0.500 & 0.687 & 0.252 & 0.688 & AB598822 \\
\hline Lc- 0 & $(\mathrm{CA})_{4} \mathrm{CG}(\mathrm{CA})_{3}$ & $\begin{array}{l}\text { F: CGACTTGAAGGAACAGCAGA } \\
\text { R: TTAGATTTCCGGCCACAGAC }\end{array}$ & 40 & 5 & $236-248$ & 50 & 0.25 & 0.65 & $* *$ & 0.586 & 0.611 & 0.183 & 0.616 & AB598823 \\
\hline
\end{tabular}

* - CCGCCGCCGACGTTATCTGCCGCCG; ** - a significant deviation from HWE was observed after Bonferroni correction for multiple comparisons $(\mathrm{P}<0.01)$. Na - the number of alleles; Ta - locus-specific annealing temperature; $H_{O}-$ observed and $H_{E}-$ expected heterozygosities; $P I C$ - polymorphism information content; $N E-2 P$ - non-exclusion probability (second parent); $N E-I-$ non-exclusion probability (identity); $F_{I S}$ - inbreeding coefficient.

Four hundred and eighty recombinant colonies were suspended in $20 \mu \mathrm{l}$ distilled water. Inserts were PCR-amplified using M13 primers (TaKaRa-Bio). One micro-liter of each amplified product was individually dropped onto a positively charged MagnaGraph nylon membrane (GE Osmonics, Minnetonka, USA). After the membrane was dried at room temperature, the DNAs were denatured by normal alkaline transfer $(0.5 \mathrm{M} \mathrm{NaOH}, 1.5 \mathrm{M} \mathrm{NaCl})$, neutralised in a buffer $(0.5 \mathrm{M}$ Tris- $\mathrm{HCl}(\mathrm{pH} 7.5), 1.5 \mathrm{M} \mathrm{NaCl})$, and cross-linked onto the membrane using a UV transilluminator. The PCR products containing microsatellite regions were detected using 5, biotin-labelled oligonucleotide probes $(\mathrm{CA})_{10}$. The length of 55 positive clones was analysed by loading $1 \mu 1$ of the remaining PCR products onto $8 \%$ polyacrylamide gels in TBE. When the estimated length of some clones was almost equal to that of other clones, we considered them as identical microsatellite regions and the duplicates were not included in the subsequent analysis. Consequently forty-eight unique inserts were detected, which ranged in size from $400 \mathrm{bp}$ to $1000 \mathrm{bp}$. The plasmids from the positive clones were sequenced using an automated sequencer, CEQ 2000XL (Beckman Coulter, Tokyo, Japan). From the 48 sequences, 21 primer pairs were designed using the online primer design software PRIMER 3.0 (Rozen \& Skaletsky, 1998).

Polymorphisms for the 21 microsatellite loci were analysed by amplification for $40 \mathrm{~L}$. (L.) coronata and $7 \mathrm{~L}$. (L.) scuterallis specimens collected from the study site, Maibara city (central Japan). Genomic DNA was extracted using a modified Chelexbased method (Walsh et al., 1991). Five micro-liter PCR reactions containing $2.5 \mu 12 \times$ GC buffer II, $0.8 \mu \mathrm{l}$ dNTP mix $(2.5$ $\mathrm{mM}$ of each dNTP), $0.5 \mu 1$ of each primer $(10 \mathrm{pmol} / \mu \mathrm{l}), 0.25 \mathrm{U}$ LA Taq (TaKaRa-Bio), $0.5 \mu \mathrm{l}$ DNA (50 ng) and $0.175 \mu 1$ sterilized, distilled water were performed. The PCR cycles were as follows: $3 \mathrm{~min}$ at $94^{\circ} \mathrm{C}, 30$ cycles of $20 \mathrm{~s}$ at $94^{\circ} \mathrm{C}, 20 \mathrm{~s}$ at $50-56^{\circ} \mathrm{C}$ (see Table 1), $1 \mathrm{~min}$ at $64^{\circ} \mathrm{C}$. The PCR products were resolved on $8 \%$ non-denaturing polyacrylamide gels by electrophoresis. A size standard, Marker 10 (pBR322/Msp I digest,
NIPPON GENE, Tokyo, Japan), was used to determine the allele sizes.

The inbreeding coefficient $\left(F_{I S}\right)$, the genotype frequency deviations from the Hardy-Weinberg equilibrium (HWE) and linkage disequilibrium were tested for each $L$. (L.) coronata locus using GenePop version 4.0.10 (Rousset, 2008). Null allele frequencies were inferred using Micro-Checker version 2.2.3 (van Oosterhout et al., 2004). To estimate loci polymorphisms, the polymorphism information content (PIC) and the non-exclusion probabilities for a second parent $(N E-2 P$, at a locus will not exclude an unrelated candidate parent from parentage of offspring when the genotype of the other parent is known) and for identity (NE-I, at a locus will not differentiate between two randomly selected individuals) were calculated using Cervus 3.0.3 (Kalinowski et al., 2007).

\section{RESULTS AND DISCUSSION}

Ten out of 21 primer pairs successfully amplified the target regions in $L$. (L.) coronata, but only nine products were polymorphic in the samples studied. The number of alleles, observed and expected heterozygosities, the polymorphism information content $(P I C)$, the non-exclusion probability $(N E-2 P, N E-I)$ and $F_{I S}$ are presented in Table 1. Significant deviations from HWE were observed in the heterozygote frequencies for all nine loci (Hardy-Weinberg exact tests, $P<0.01$ after Bonferroni correction for multiple comparisons) and all loci exhibited a heterozygote deficiency. Micro-Checker detected significant null allele frequency at all loci. Null allele frequencies estimated using Brookfield's method 1 (Brookfield, 1996) ranged from 0.17 to 0.34 . Linkage disequilibrium was not detected for any loci pairs when Fisher's exact probability test with a Bonferroni correction for multiple comparisons was used $(P<0.01)$. The nonexclusion probabilities of a second parent and identity of the nine loci were 0.011 and $<0.001$, respectively.

The presence of null alleles at all loci could account for the observed heterozygote deficiency and high $F_{I S}$ value. Inbreeding and the Wahlund effect may also result in a heterozygote deficiency. Additionally other genotyping errors caused by sto- 
chastic sampling errors would result in a heterozygote deficiency due to low template DNA concentrations (summarised in van Oosterhout et al., 2004). Although we observed a heterozygote deficiency at all nine loci, the Cervus software showed sufficient statistical power to determine paternity. The non-exclusion probabilities ( $N E-2 P$ and $N E-I)$ for all nine loci yielded a low value, which was permissive for determining the paternity of offspring resulting from sequential copulation experiments using two different males. The presence of null alleles may cause an inconsistency between mothers and offspring pairs (Pemberton et al., 1995; Dakin \& Avise, 2004), although this effect can be minimized by combining the nine isolated loci in the experimental design.

To understand evolutionary processes involved in sexual selection, it is necessary to determine whether polyandry occurs in the wild as well as in laboratory mating experiments. Comparing the genetic diversity of offspring from females collected in the wild and laboratory-reared females could provide an estimate of the probability of polyandry occuring in field populations (Kamimura, 2003). The nine microsatellite loci provide a valuable source of markers for such comparative analyses. However, since the extent of the polymorphism at each locus was not the same, greater priority should be placed on using more polymorphic loci in future analyses.

In $L$. (L.) scutellaris, five primer sets (Lc-1, Lc-6-9) successfully amplified the target regions and detected polymorphisms in four out of the five primer sets. The two species breed sympatrically at the study site, although they can be clearly differentiated by significant differences in the length of the elongated parts of their genitalia. In Ohomopterus ground beetles, Takami $\&$ Sota (2007) verified that marked differences in closely related species are facilitated by the interaction between inter- and intra-sexual selection processes. The isolated markers will enable us to compare the selection pressure operating on these two closely related sympatric species.

ACKNOWLEDGEMENTS. Y.M. would like to thank T. Kanbe for his valuable technical suggestions and A. Ohtsuki and S. Akimoto for their assistance. This study was supported by a JSPS Research Fellowship for Young Scientists to Y.M. and a Grant-in-Aid for Scientific Research (C) (No. 21570012 to IY).

\section{REFERENCES}

ARNQVIST G. 1997: The evolution of animal genitalia: distinguishing between hypotheses by single species studies. Biol. J. Linn. Soc. 60: 365-379.

ARnqvist G. \& DANIELSSON I. 1999: Copulatory behavior, genital morphology and male fertilization success in water striders. Evolution 53: 147-156.

BROOKFIELD J.F. 1996: A simple new method for estimating null allele frequency from heterozygote deficiency. Mol. Ecol. 5: 453-455.

DAKIN E.E. \& AviSE J.C. 2004: Microsatellite null alleles in parentage analysis. Heredity 93: 504-509.

Danielsson I. \& Askenmo C. 1999: Male genital traits and mating interval affect male fertilization success in the water strider Gerris lacustris. Behav. Ecol. Sociobiol. 46: 149-156.

Eberhard W.G. 1985: Sexual Selection and Animal Genitalia. Harvard University Press, Cambridge, MA, 244 pp.

Fischer D. \& BACHMANN K. 1998: Microsatellite enrichment in organisms with large genomes (Allium cepa L.). Biotechniques 24: 796-802.
Gschwentner R. \& TAdLeR A. 2000: Functional anatomy of the spermatheca and its duct in the seed bug Lygaeus simulans (Heteroptera: Lygaeidae). Eur. J. Entomol. 97: 305-312.

Hosken D.J. \& Stockley P. 2004: Sexual selection and genital evolution. Trends Ecol. Evol. 19: 87-93.

Kalinowski S., Taper M. \& Marshall T. 2007: Revising how the computer program CERVUS accommodates genotyping error increases success in paternity assignment. Mol. Ecol. 16: 1099-1106.

KAMIMURA Y. 2003: Effects of repeated mating and polyandry on the fecundity, fertility and maternal behaviour of female earwigs, Euborellia plebeja. Anim. Behav. 65: 205-214.

KAmimuRA Y. 2005: Last-male paternity of Euborellia plebeja, an earwig with elongated genitalia and sperm removal behavior. J. Ethol. 23: 35-41.

Kiмoto S. \& Takizawa H. 1994: Leaf Beetles (Chrysomelidae) of Japan. Tokai University Press, Tokyo, 540 pp. [in Japanese with English keys and brief synonym list].

Matsumura Y. \& Акімото S. 2009: Mating behavior and genital damage during copulation in the leaf beetle Lema coronata (Chrysomelidae, Criocerinae). Entomol. Sci. 12: 215-217.

Matsumura Y. \& Suzuki K. 2008: Comparative morphology of internal reproductive systems in leaf beetles of the Donaciinae and Criocerinae (Coleoptera: Chrysomelidae) and its implication for the phylogeny. Zootaxa 1845: 1-32.

Oosterhout C. van, Hutchinson W.F., Wills D.P.M. \& Shipley P. 2004: MICRO-CHECKER: Software for identifying and correcting genotyping errors in microsatellite data. Mol. Ecol. Notes 4: 535-538.

Pemberton J.M., Slate J., Bancroft D.R. \& Barrett J.A. 1995: Nonamplifying alleles at microsatellite loci: a caution for parentage and population studies. Mol. Ecol. 4: 249-252.

Rodriguez V., Windsor D. \& Eberhard W.G. 2004: Tortoise beetle genitalia and demonstration of a selected advantage for flagellum length in Cherymorpha alternans (Chrysomelidae, Cassidini, Stolaini). In Jolivet P., Santiago-Blay J.A. \& Schmitt M. (eds): New Developments in the Biology of Chrysomelidae. SBP Academic Publisher, The Hague, pp. 739-748.

Rousset F. 2008: Genepop'007: a complete reimplementation of the Genepop software for Windows and Linux. Mol. Ecol. Resour. 8: 103-106.

Rozen S. \& Skaletsky H.J. 1998: PRIMER 3.0. Whitehead Institute for Biomedical Research, Cambridge, MA. Code available at: http://frodo.wi.mit.edu/primer3/

TADLER A. 1999: Selection of a conspicuous male genitalic trait in the seedbug Lygaeus simulans. Proc. R. Soc. Lond. (B) 266: 1773-1777.

TAKAMI Y. 2007: Spermatophore displacement and male fertilization success in the ground beetle Carabus insulicola. Behav. Ecol. 18: 628-634.

TAKAмI Y. \& Sota T. 2007: Rapid diversification of male genitalia and mating strategies in Ohomopterus ground beetles. $J$. Evol. Biol. 20: 1385-1395

Walsh P.S., Metzger D.A. \& Higuchi R. 1991: Chelex ${ }^{\circledR} 100$ as a medium for simple extraction of DNA for PCR-based typing from forensic material. Biotechniques 10: 506-513.

Zane L., Bargelloni L. \& Patarnello T. 2002: Strategies for microsatellite isolation: a review. Mol. Ecol. 11: 1-16.

Received November 11, 2010; revised and accepted April 19, 2011 